\title{
Reflexive Competence in Metacognitive Monitoring of Learning Activity of HEl Students
}

\author{
Eduard Balashov ${ }^{1 *}$, Ihor Pasichnyk1, Ruslana Kalamazh1, Tetiana Zdrobylko ${ }^{1}$
}

\begin{abstract}
'Department of Psychology and Pedagogy, National University of Ostroh Academy, Ostroh, Rivne Region, Ukraine, e-mail: eduard.balashov@oa.edu.ua; oa@oa.edu.ua; ruslana.kalamazh@oa.edu.ua; tetiana.zdrobylko@oa.edu.ua
\end{abstract}

\begin{abstract}
The manuscript presented here reports the theoretical aspects of the concepts of reflexive competence and reflexivity, which is considered, in learning activities through a prism of metacognitive monitoring of HEI students. An essence of metacognitive monitoring and reflexive competence has been theoretically studied. The role of reflexive competence and its components in the process of metacognitive monitoring of the educational activities of students of HEls has been described. Reflexive competence at the metacognitive level is viewed as a system of formed reflexive abilities, which ensures high productivity of the intellectual activity of the subject by activating the metacognitive resources that are necessary and organizing reflexive actions. The results of empirical research with the use of questionnaire "Reflexive skills (cognitive and metacognitive level scales) (O. Savchenko), Methodology "Reflexive strategies of task solution" (O. Savchenko and M. Makiienko), Metacogntive Awareness Inventory - MAI (G. Scraw and R. Dennison) and "Methodology of Self-Evaluation of Metacognitive Knowledge and Metacognitive Activeness" (M. Kashapov \& Y. Skvortsova), and correlation analysis with the use of ANOVA analysis of variance and Spearmen's rank correlation coefficient, have proved that student's overconfidence can cause mistakes in the evaluation of the results of the work. Senior students have better indicators of reflexive skills at the metacognitive level and more sophisticated reflexive problem-solving strategies. Thus, the results indicate that senior students have a higher level of reflexive skills at the metacognitive and cognitive levels and a higher level of reflexive problem-solving strategies than the first- and second-year students.
\end{abstract}

Keywords: reflexivity, reflexive competence, self-regulation, metacognitive monitoring, learning activity.

\section{Introduction}

The current stage of educational development is characterized by a focus on the competencybased approach in the preparation of graduates. The student must have not only a certain amount of knowledge but also be oriented towards self-improvement, self-development, and self-actualization. Besides this, upon graduation, students are expected to possess the various competencies required for further professional activity. Reflection has recently become one of the basic competencies in the education system and has lately been actively studied by scholars along with other concepts such as reflexivity and reflexive abilities. The main function of reflexive competence, as the ability to observe and control one's own actions and decision-making process, is the most effective and adequate implementation of reflexive processes; the realization of reflexive ability, which provides the process of development and self-evolution, promotes creativity to professional activity and achievement of its maximum efficiency and performance. There is a link between metacognitive monitoring and reflexive competence, and it should be noted that due to the existence of a set of reflexive skills, metacognitive processes can be implemented.

The aim of this article is to study the role of reflexive competence and its components in the process of metacognitive monitoring of the educational activities of students of higher education institutions (HEI).

The concepts mentioned above are considered mainly as a professional quality of personality in the context of pedagogy, educational psychology, general psychology and cognitive psychology. In particular, the reflexive processes have been studied by such as the following national psychologists Balashov, 2019; Dotsevych, 2014; Balashov et al., 2018; Maksymenko, 2017; Pasichnyk et al., 2014; Savchenko, 2016; Tytarenko, 2013. Self-reflection and metacognition at the personal level is considered in the studies of Dunlosky and Metcalfe, 2009; Hrynkiv, 2016; Karpov, 2012; Kholodnaya, 2002; Koriat and Bjork, 2005.

The phenomenon of reflexive competence was developed by such scholars as Babaian, 2014;

*Corresponding author: eduard.balashov@oa.edu.ua 
Dotsevych, 2014; Leontyev and Averina, 2011. In her works, O. Savchenko investigated and characterized the components and levels of reflexive competence (Savchenko, 2016).

Nowadays, studies of metacognitive processes include the theoretical and empirical analysis of various issues that reflect the role of metacognitive activity in learning activities. Issues of metacognition and metacognitive monitoring, namely, the functions and structural components of these phenomena, self-efficacy and learning strategies have been studied by foreign and domestic scholars (Andrade and Heritage, 2018; Avhustiuk, 2016; Bandura, 1997; Bembenutty et al., 2013; Dabbagh and Kitsantas, 2013; Flavell, 1979; Schunk, 1987; Winne, 2010; Zabrucky, 2010; Zimmerman and Schunk, 2011). R. Ryan and E. Deci studied self-determination and basic psychological needs of a subject in motivation, development and wellness (Ryan and Deci, 2017). The link between metacognitive monitoring and the success and productivity of the learning activity in the context of studying the accuracy and reliability of this process is the main problem that is explored in this field (Dunlosky and Metcalfe, 2009; Fomin, 2012; Koriat and Bjork, 2005; Nietfeld et al., 2005; Savin, 2011; Valdez, 2013). The connection between reflection and the metacognitive experience of personality has been indicated by Dovhaliuk and Voloshyna, 2015; Dotsevych, 2014; Karpov, 2012; Kholodnaya, 2002; Pasichnyk and Dovhaliuk, 2016; Savin and Fomin, 2011.

Reflexive competence is a relatively new concept in scientific literature, so it is necessary, for a more detailed understanding, to refer to the concepts which form its basis: reflection and reflexivity. Self-reflection, as a process, refers to the regulatory component of the subject and consists of the selfknowledge of the subject's own internal mental acts and states. In general, reflection is self-oriented. In philosophy, reflection (from the Latin reflexio - "bending back") is considered as a person's process of thinking about his or her consciousness. In psychology, there are also other interpretations of this concept. As the most promising approach of explaining the phenomenon of reflection, we have defined that in which reflection is the general capacity of the individual which provides the opportunity to "interrupt this continuous process of life and bring the person mentally beyond its limits". The study of reflexive processes has faced some challenges because the methodological toolkit is not well developed to study all aspects of this phenomenon. Besides, the concept of reflection according to A. Karpov has several modes, namely: a reflective mechanism, reflection as a process, reflection as a state and reflexivity as a personal ability (Hrynkiv, 2016).

Reflexive competence is an integrative personal formation. Its formation occurs through the acquisition of reflexive experience by the subject, whose main function is to coordinate other components of the experience and ensure the effective use of reflexive skills in the process of the activity. The reflexive competence of a person is understood by the subject mastered through a set of qualities, both professionally and personally important, which are formed directly during the reflexive activity. There are three levels of reflexive activity ( 0 . Savchenko): cognitive (understanding of the nature of the flow and grounds of one's intellectual activity), metacognitive (providing regulation of the external and internal activity of the subject), and personal (self-knowledge and self-expression of personality).

There are also its four components:

1) informative, which is about the awareness of individuals regarding the features of their personality that are important in using the information available to ensure the efficiency and effectiveness of the process of solving the problem and making a decision.

2) instrumental, which includes skills aimed at regulating the subject's learning activity. In this component, the main mechanism is the actual process of reflection.

3 ) assessment-motivational, characterized mainly by prognostic abilities, which are manifested in three processes: probabilistic programming, expectations, anticipation. Predictive features are influenced by one's personal qualities as well as the development of the subject's cognitive and metacognitive skills.

4) behavioral, that is, the activation of the formed skills and abilities of the subject in order to apply it to the process of problem-solving or decision-making (Savchenko, 2016).

Organizational psychology offers another interpretation of reflexive competence; in particular, it is considered to be the ability to regulate mental activity (Leontyev and Averina, 2011). Its essence, according to Y. Babaian, lies in using deep versatile analysis to enable awareness of its vocation, further self-fulfillment in the appropriate direction, and establishment of the social value of the result of its activity (Babaian, 2014). According to T. Nelson and L. Narens, reflexive competence is the professional quality of a person which provides the most effective and adequate realization of the reflexive processes and of the reflexive capacity that promotes the development and self-evolution of the subject. It ensures the use of a creative approach in professional activity and the achievement of its maximum efficiency and effectiveness (Nelson and Narens, 1990).

Along with the essence of reflexive competence, scholars consider the essence of metacognitive 
monitoring, which also refers to the regulatory component of the activity. Metacognitive monitoring is a part of the "metacognition" system, and the study of metacognitive processes began from this development/ discovery (Hrynkiv, 2016). The first researcher to examine and develop the structure of metacognition was J. Flavell. He considered metacognitive processes as a system of human knowledge about the characteristics of his or her cognitive sphere and ways of controlling it, and distinguished four classes of phenomena: (a) metacognitive knowledge, (b) metacognitive experience, (c) goals (or tasks), (d) actions (or strategies). The first two components are reflexive formations, through which human intelligence acquires some new quality, called by J. Flavell "cognitive monitoring", which he explains as the ability to view introspectively and track the progress of intellectual activity. The scholar points to the advantage of the regulatory function of metacognitive processes and attaches particular importance to reflection (Flavell, 1979).

In psychology, metacognitive monitoring is considered to be the process of observing the course of one's thinking processes, of one's learning activity directly in the process of solving problems or making a decision, as well as the results of one's learning activity (Avhustiuk, 2016). The main feature is the presence of conscious and meaningful observation of the course of one's thoughts and actions; that is, the active position and control by the subject of activity. Metacognitive monitoring performance criteria include the subject's ability to prioritize tasks, evaluate the amount of time and effort needed to solve a problem and organize ongoing control over intellectual activity. It is worth noting that among scholars there are different points of view on the essence of metacognitive monitoring. Some of the researchers see it as a process (Avhustiuk, 2016; Balashov et al., 2018; Nelson and Narens, 1990; Pasichnyk et al., 2014; Savin and Fomin, 2011).

Despite the broad coverage of these concepts in scientific literature, there is no united view of their correlation. There are several views, two of which are the principal: the first one is that reflexive competence is a broader concept and involves the process of metacognitive monitoring; the second approach considers metacognition and metacognitive monitoring to be the broader concepts; that is, reflexive skills form an element that makes it possible to set and implement metacognitive monitoring. The connection between reflection and the metacognitive experience of personality has been investigated by Dotsevych, 2014; Pasichnyk and Dovhaliuk, 2016; Karpov, 2012; Kholodnaya, 2002; Savin and Fomin, 2011; Dovhaliuk and Voloshyna, 2015. The main contribution of these scholars is that the basis of acquisition of metacognitive experience is a reflection of mental activity (Fomin, 2011). In the works of T. Dotsevych, it is stated that reflexivity is an important factor in organizing all metacognitive experience, through which metacognitive involvement and awareness are activated (Dotsevych, 2014). A. Karpov points to the uniqueness of the issue of reflection and proposes to view reflexivity as a meta-skill that performs a regulatory function and is at the highest systemic level in the structure of all mental processes (Karpov, 2012).

At the metacognitive level, reflexive activity is manifested in the subject's ability to organize monitoring of a current activity in order to consciously monitor the progress of the activity and its results. The ability to analyze, comprehend and understand past experiences, mistakes, and successes, which is a reflexive competence, helps to gain new experience, new knowledge in the learning process and to gain new success (Babaian, 2014). A high level of organization of reflexive competence promotes the organization of more effective forms of reflexive activity through realization of the ability to create probable models of problem-solving, to carry out self-analysis of one's actions, to activate abilities to understand the consequences of the events of one's own life, and to use more time for decision-making in multiple control situations to evaluate one's own intellectual abilities (Balashov, 2019).

\section{Materials and Methods}

The empirical study we conducted was to diagnose the instrumental and behavioral components of reflexive competence, as well as the metacognitive characteristics (involvement, activity, and metacognitive knowledge) of the subjects of learning activity. The study was conducted at the National University of Ostroh Academy, and empirical data was collected during June-August 2019. The sample population was formed by a spontaneous method from the full-time students of all years of study. Thus, 62 respondents ( 9 males and 53 females) regardless of major, aged from 17 to 24 years $(M=20,71, S D=1,868)$ participated in the study. To analyze the empirical data, the sample population was divided into three groups according to the year of study:

1. the first group - first and second years of study $(N=22 ; M=19,32 ; S D=1,673)$;

2. the second group - third and fourth years of study $(N=18 ; M=20,50 ; S D=1,543)$; 


\section{3. the third group - the fifth and sixth years of study ( $N=22 ; M=22,27 ; S D=0,883)$.}

To study the above indicators, we selected the following methods:

Method \#1 - "The reflexive skills (metacognitive level)" (0. Savchenko). In order to study the level of development of students' reflexive skills according to O. Savchenko's classification, namely: the ability to organize the process of problem-solving, to direct efforts towards achieving the goal; the ability to predict possible mistakes and difficulties, to analyze one's capabilities; the ability to regulate one's emotional states, to set mind to work; the ability to plan, evaluate and validate one's actions; the ability to create probabilistic models of problem-solving, to carry out self-analysis of one's actions, peculiarities of one's behavior; the ability to monitor current forms of mental activity, to regulate the significance of the problem taking into account the current state; the ability to critically evaluate one's intellectual abilities, capabilities, and limitations, as well as the overall level of development of reflexive metacognitive skills.

Method \#2 - "The reflexive skills (cognitive level)" in the development of O. Savchenko, which allowed determination of the level of formation of the following reflexive skills: the ability to explain to yourself and others the course of your reasoning and reasons for choosing a certain solution or strategy; the ability to be aware of your own emotional experiences, to control their course, to maintain a sense of confidence; the ability to keep oneself in the plane of reflexive reasoning, to analyze the reasons for one's own actions and the causes of failures; the ability to regulate the process of finding a solution, to verify one's assumptions; the ability to evaluate results by various criteria, formulate judgments; the ability to be aware of various aspects of the decision-making process: cognitive, emotional, behavioral, as well as the general level of development of reflexive cognitive skills.

Method \#3 - "The reflexive strategies of problems solving" (O. Savchenko, M. Makiienko), which contains 8 scales corresponding to various reflexive strategies for solving problems. Four scales correspond to primary strategies: deep processing of information, censoriousness in the analysis and evaluation of information, decision-making with an orientation to internal standards, and a rational approach to finding a solution to a problem.

The following four scales are complex and combine the primary strategies that we have indicated above.

1. "Metacognitive Awareness Inventory" G. Schraw \& R. Dennison (MAI) was used to evaluate the level of development of human reflexive functions, how they affect activity, namely the pattern of their participation in human activity.

2. Method of diagnosis for self-assessment of metacognitive knowledge and metacognitive activity (M. Kashapov \& Y. Skvortsova) consisting of two scales:

1) Metacognitive knowledge, which the authors understand as knowledge about their cognitive processes, namely knowledge about the means of obtaining and processing information, the type and content of tasks and requirements for its solution, about a person's ability to obtain metacognitive strategies.

2) Metacognitive activity is directly represented by the processes of human activity: obtaining and selecting information, controlling, transforming and planning metacognition.

The accuracy and validity of the research, which was executed with the use of MS Excel 2010 and StatSoft STATISTIKA 21, was ensured by representativeness of the sample, the use of the methods relevant to the topic, aim and tasks of the study, the use of quantitative and qualitative analysis of the received empirical data by using the following methods of mathematical statistics.

- descriptive statistics - calculated indicators, which allow to determine the distribution of values of the variable. We used it to describe our sample and indicators of the development of reflexive skills, strategies and metacognitive characteristics in different groups of respondents. The following indicator from the first group was informative for our study: the indicator of evaluation of the central tendency - the average value (the sum of all values of the variable divided by their number); and the indicator of the second group, which characterized the variability of the variable values related to its mean - the standard deviation (square root of dispersion),

- the one-factor dispersion analysis of variance (ANOVA) for searching for statistically significant dependencies/differences in the indicators by the methodologies described above, among the students of different years of study. We can confirm that in the presence of statistically significant differences between two indicators, their development occurs differently, as the certain indicator is usually higher that another, therefore, the development of the certain skill happens faster and so on.

- Spearman's correlation coefficient for evaluation of the indicators of metacognitive functions, particularly metacognitive activity, knowledge and involvement to activity, and the indicators of formation of students' reflexive skills of cognitive and metacognitive level and reflexive strategies for solving the 
tasks. Correlation is a statistical indicator that allows determining and evaluating the probabilistic relations between two variables. It should be noted that the peculiarity of the probabilistic relation is that one value of a certain variable corresponds to a number of values of another variable. The presence of a positive direct correlation indicated that the increase of indicator of one value cause the increase of such indicator of another one.

\section{Results}

In our research with the use of one-factor dispersion analysis of variance ANOVA and the results of descriptive statistics, we evaluated the level of development of cognitive-level reflexive skills by the methodology developed by $\mathrm{O}$. Savchenko. Thus, the development of a high level of ability to explain to yourself and others the course of your reasoning, the reasons for choosing a particular solution and strategy is observed at the third and fourth years of study $(M=2.50, S D=0.514)[F(2,56)=10.164, p=0,000]$. The indicators of the greatest ability to recognize one's own emotional experiences, control their course and maintain a sense of confidence $[F(2,56)=12,188, p=0,000]$ are observed in the first years of study $(M=2.71, S D=0.463)$, and subsequent years' indicators are statistically significantly lower and remain at the same level: third and fourth years of study ( $M=2.00, S D=0.000)$, master's course $(M=2.00, S D=0.775)$. Studying the general level of development of reflexive skills at a cognitive level, we determined that in the last years of study (master's program) $(M=1.71, S D=0.717)$, the indicators are the lowest $[F(2,56)=5.601$, $p=0.006]$. Thus, we refute the hypothesis according to which senior students (graduate students) have a higher level of formation of reflexive skills at the cognitive level compared to first- and second-year students. We cannot argue the fact that the level of development of cognitive skills decreases throughout the study. To verify and confirm this statement it is necessary to conduct a longitudinal study and track the development of skills. in Figure 1.

Graphically, the results of the study by the method "The reflexive skills (cognitive level)" are shown

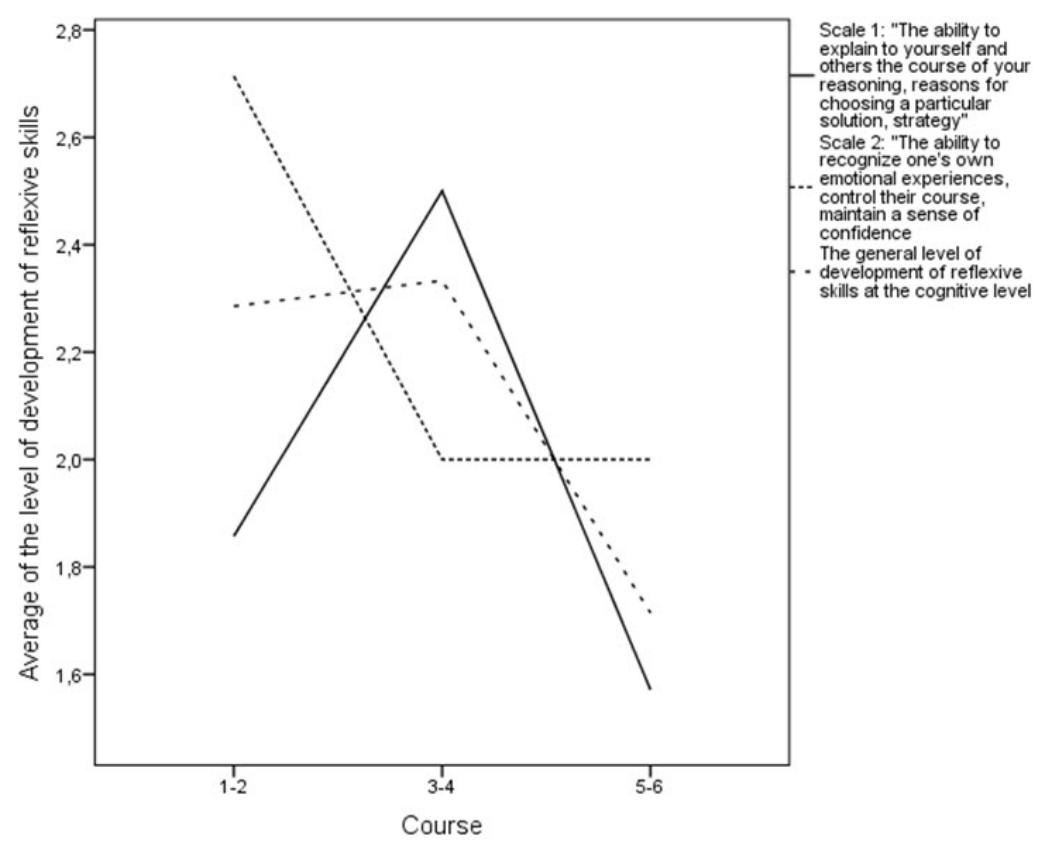

Figure 1. The results of the method "The reflexive skills (cognitive level)" (O. V. Savchenko) among students in accordance with the curriculum with the use of one-factor dispersion analysis of variance ANOVA

If we take into account the results of correlation analysis with the use of Spearmen's correlation coefficient, according to which the general level of development of reflexive skills at the cognitive level has a negative weak correlation with metacognitive involvement $(r=-0.274, p=0.031)$, then we can say that with a higher focus on cognitive skills, students become less involved in metacognitive activity (Table 1). The results can be interpreted as follows: senior students have more automatic cognitive skills, students begin to focus more on metacognitive observations, that is, on the process of metacognitive monitoring.

It is worth noting that metacognitive activity does not correlate with any reflexive skill at the cognitive 
level. As you can see, these skills do not relate to working with information and actually solving problems but are focused on observing and tracking emotional experiences, searching for the causes of failures, and the like. Thus, the hypothesis about the existence of a positive relationship between the metacognitive characteristics (knowledge) of the subject's activity and the formed reflexive skills of the cognitive level is partially confirmed; however, the metacognitive involvement has a negative relationship with reflexive skills.

Table 1

The results of correlation analysis with the use of Spearmen's correlation coefficient on the relation between metacognitive characteristics and reflexive skills at the cognitive level

\begin{tabular}{|c|c|c|}
\hline & $\mathbf{R}$ & $\mathbf{P}$ \\
\hline \multicolumn{3}{|l|}{ Metacognitive involvement * } \\
\hline $\begin{array}{l}\text { The ability to keep oneself in the plane of reflective reasoning, analyze the } \\
\text { reasons for one's own actions, causes of failures }\end{array}$ & 0,331 & 0,009 \\
\hline Metacognitive involvement * & & \\
\hline $\begin{array}{l}\text { The ability to regulate the process of finding a solution, to verify one's } \\
\text { assumptions }\end{array}$ & $-0,268$ & 0,035 \\
\hline $\begin{array}{l}\text { Metacognitive involvement * } \\
\text { The general level of development of reflexive skills at the cognitive level } \\
\text { Metacognitive knowledge * }\end{array}$ &,- 0274 & 0,031 \\
\hline $\begin{array}{l}\text { The ability to recognize one's own emotional experiences, control their course, } \\
\text { maintain a sense of confidence } \\
\text { Metacognitive knowledge * }\end{array}$ & 0,342 & 0,007 \\
\hline $\begin{array}{l}\text { The ability to keep oneself in the plane of reflexive reasoning, to analyze the } \\
\text { grounds of one's own actions, the causes of failures } \\
\text { Metacognitive knowledge * }\end{array}$ & 0,374 & 0,003 \\
\hline $\begin{array}{l}\text { The ability to regulate the process of finding a solution, to verify one's } \\
\text { assumptions }\end{array}$ & 0,309 & 0,015 \\
\hline
\end{tabular}

This is confirmed by the correlation results with the use of SpearmeFn's correlation coefficient, according to which metacognitive knowledge has a positive moderate relationship with the following reflexive skills: to be aware of one's own emotional experiences, control their course, maintain a sense of confidence $(r=0.342, p=0.007)$, keep oneself in the plane of reflexive reasoning, analyze the grounds of one's own actions and the reasons of failures $(r=0.374, p=0.003)$, as well as to regulate the process of finding a solution and verify one's own assumptions $(r=0.309, p=0.015)$.

In addition, we investigated the level of development of reflexive skills at the metacognitive level according to the method of O. Savchenko in the context of the student's year of study with the use of one-factor dispersion analysis of variance ANOVA and the results of descriptive statistics. We found that students demonstrated a higher level of development of the ability to organize the process of solving the problem and direct efforts to achieve the goal $[F(2,56)=4.979, p=0.010]$ in the third/fourth years of study $(M=2.33, S D=0.767)$, and the lowest rates are in the last years of study $(M=1.86, S D=0.359)$. On a scale that measures the level of development of the ability to predict possible errors and difficulties and to analyze one's own capabilities, a gradual increase in indicators is observed $[F(2,56)=0.709$, $p=0.013]$ throughout the entire period of students' education: in the first years, the indicators are as follows: $(M=2,14 S D=0.359)$, in the third/fourth year $(M=2.33, S D=0.485)$ and in the master's course $(\mathrm{M}=2.57, \mathrm{SD}=0.507)$. The lowest indicators of the level of development of the ability to plan, evaluate and verify one's own actions, $[F(2,56)=4.979, p=0.010]$ are observed in the first years $(M=1.71, S D=0.717)$, and the highest in third/fourth year $(M=2.33, S D=0.485)$. Studying the general level of the development of reflexive skills at the metacognitive level study, with the use of one-factor dispersion analysis of variance ANOVA and the results of descriptive statistics, we found that the development rates of reflexive skills at the third / fourth year $(M=2.33, S D=0.767)$ are statistically significantly higher $[F(2,56)=7.410, p=0.001]$ than the last years of study (master's program) $(M=2.29, S D=0.463)$. Informative is the observation that predominantly third- and fourth-year students showed better results than graduate students by the method. Thus, we confirm the hypothesis that senior students (master's program) have a higher level of formation of reflexive skills at the metacognitive level, compared with first- and second-year students. Graphically, the results of the study using the method "The reflexive skills (metacognitive level)" are shown in Figure 2. 
If we take into account the results of correlation analysis by Spearmen's correlation coefficient, it is worth noting that the ability to predict possible mistakes and difficulties, analyze one's own capabilities $(r=0.372, p=0.003)$, as well as the ability to create probabilistic models of solving the problem, to carry out self-analysis of one's own actions and behavioral characteristics $(r=0.327, p=0.009)$ have a positive moderate connection with metacognitive activity. That is, the more active a student's metacognitive activity, the higher is the level of development of this skill.

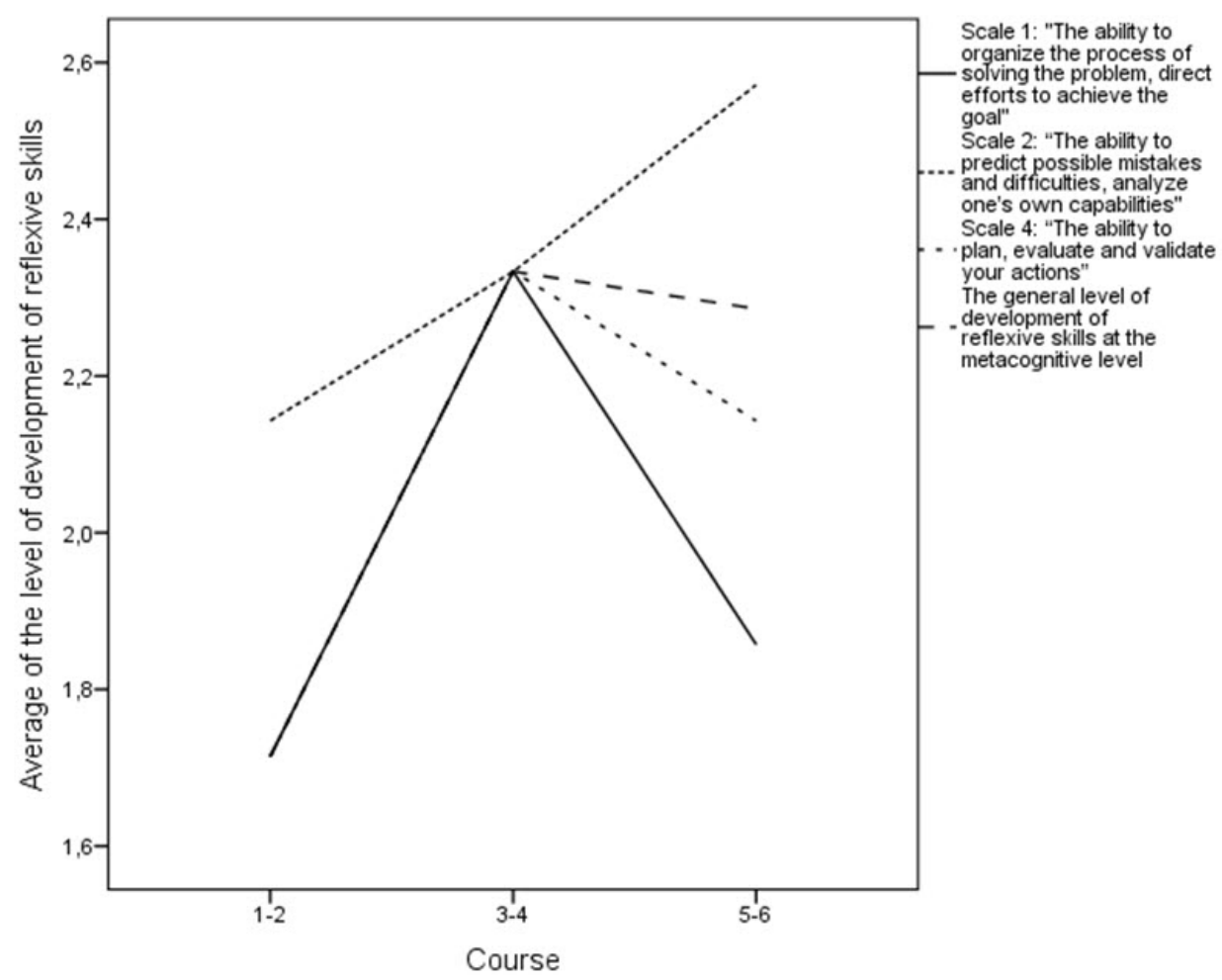

Figure 2. The results of the method "The reflexive skills (metacognitive level)" (O. V. Savchenko) among students in accordance with the curriculum study with the use of one-factor dispersion analysis of variance ANOVA

At the same time, the ability to regulate one's own emotional states and setting one's own mind to work has a negative weak link with metacognitive inclusion $(r=-0.278, p=0.029)$ and activity $(r=-0.268$, $p=0.035$ ), as well as between the general level of development of reflexive skills at a metacognitive level and metacognitive knowledge $(r=-0.281, p=0.027)$ (see Tab. 2$)$. That is, there is some probability that the more a student is involved in metacognitive activity, the less he can regulate his or her emotions. So, the hypothesis of the existence of a positive connection between the metacognitive characteristics (activity) of the subject's activity and the reflexive skills formed at the metacognitive level is partially confirmed. It is worth noting that such a metacognitive characteristic as metacognitive knowledge is associated only with the general level of the development of reflexive skills but does not correlate with any reflexive skills.

According to the results of the analysis of the method of diagnosis for self-assessment of metacognitive knowledge and metacognitive activity of M. M. Kashapov and Y. V. Skvortsova with the use of one-factor dispersion analysis of variance ANOVA, statistically significant differences were determined on the metacognitive activity scale [F=3,266, $p=0,0,45]$. Using the results of descriptive statistics, we can confirm that the lowest rates are among first- and second-year students $(M=2.95, S D=0.203)$, and the highest are among third- and fourth-year students ( $M=3.50, S D=0.514)$. 
Balashov et al. (2020). Reflexive competence in metacognitive monitoring of learning activity of HEI students, International Journal of Cognitive Research in Science, Engineering and Education (IJCRSEE), (8), Special issue of Current Research and Trends in Cognitive Sciences 2020, 17-28.

\section{Table 2}

The results of the correlation analysis with the use of Spearmen's correlation coefficient on the connection between metacognitive characteristics and reflexive skills at the metacognitive level

\begin{tabular}{|c|c|c|}
\hline & $\mathbf{R}$ & $\mathbf{P}$ \\
\hline $\begin{array}{l}\text { Metacognitive involvement * } \\
\text { The ability to regulate one's own emotional states, set mind to work }\end{array}$ & $-0,278$ & 0,029 \\
\hline $\begin{array}{l}\text { Metacognitive knowledge * } \\
\text { The general level of development of reflexive skills at the metacognitive level } \\
\text { Metacognitive activity * }\end{array}$ & $-0,281$ & 0,027 \\
\hline $\begin{array}{l}\text { The ability to predict possible mistakes and difficulties, analyze one's own } \\
\text { capabilities }\end{array}$ & 0,372 & 0,003 \\
\hline $\begin{array}{l}\text { Metacognitive activity * } \\
\text { The ability to regulate one's own emotional states, set mind to work } \\
\text { Metacognitive activity * }\end{array}$ & $-0,268$ & 0,035 \\
\hline $\begin{array}{l}\text { The ability to create probabilistic models of solving a problem, to carry out self- } \\
\text { analysis of one's actions, features of one's behavior }\end{array}$ & 0,327 & 0,009 \\
\hline
\end{tabular}

On the metacognitive knowledge scale, no statistically significant differences were found.

When studying reflexive problem-solving strategies with the use of one-factor dispersion analysis of variance ANOVA, we found that, in general, senior students have a higher plane of intelligence in particular on the scale of deep processing of information [ $F=7.563, p=0.001]$, where statistically significant high rates were found in third-, fourth-year students $(M=2.33, S D=0.114)$, and the lowest among first- and second-year students $(M=1.55, S D=0.157)$, which is confirmed by the indicator of descriptive statistics Indicators on the decision-making scale with a focus on internal standards [F=9.898, $p=0.000]$ are also the highest among the third- and fourth-year students $(M=2.17, S D=0.167)$, and the lowest among the first- and second-year students $(M=1.86, S D=0.136)$. On a scale of in-depth information processing, the results are similar: indicators are statistically significantly higher $[F=4,158, p=0,020]$ for the third- and fourth-year students $(M=2.33, S D=0.181)$, and the lowest for the first- and second-year students $(M=1.82$, $\mathrm{SD}=0.142$ ). Thus, we can note that senior students are more capable of evaluating their own strengths, they have prevailing ideas and views on certain events, ways of solving problems and making decisions, and they are less focused on the opinions and ideas of others, which confirms the hypothesis that senior students (master's program) have a higher level of formation of reflexive strategies of solving the problem, compared with the first- and second-year students. For senior students, there is great variability in the ways of solving the problem, and productivity is important for them, therefore they are more likely to analyze the causes of difficulties or failures. However, they may be negligent in the process of solving the problem at the stage of familiarization with the task conditions. They often take risks because they try to rely on their own strengths and act intuitively, but such behavior is not always justified. A graphical representation of the results is shown in Fig. 3.

If we observe the results of correlation analysis with the use of Spearmen's correlation coefficient, it is worth noting that most of the scales according to the method have a positive link with all metacognitive characteristics that we determined in the study; in particular, the comprehensive strategy, "A rational approach to solving problems with orientation to internal standards", correlates with all metacognitive characteristics. It has a positive moderate relationship with metacognitive activity $(r=0.306, p=0.016)$, a positive weak link with metacognitive knowledge $(r=0253, p=0.048)$ and a positive strong link with metacognitive inclusion $(r=0.722, p=0,000)$. 


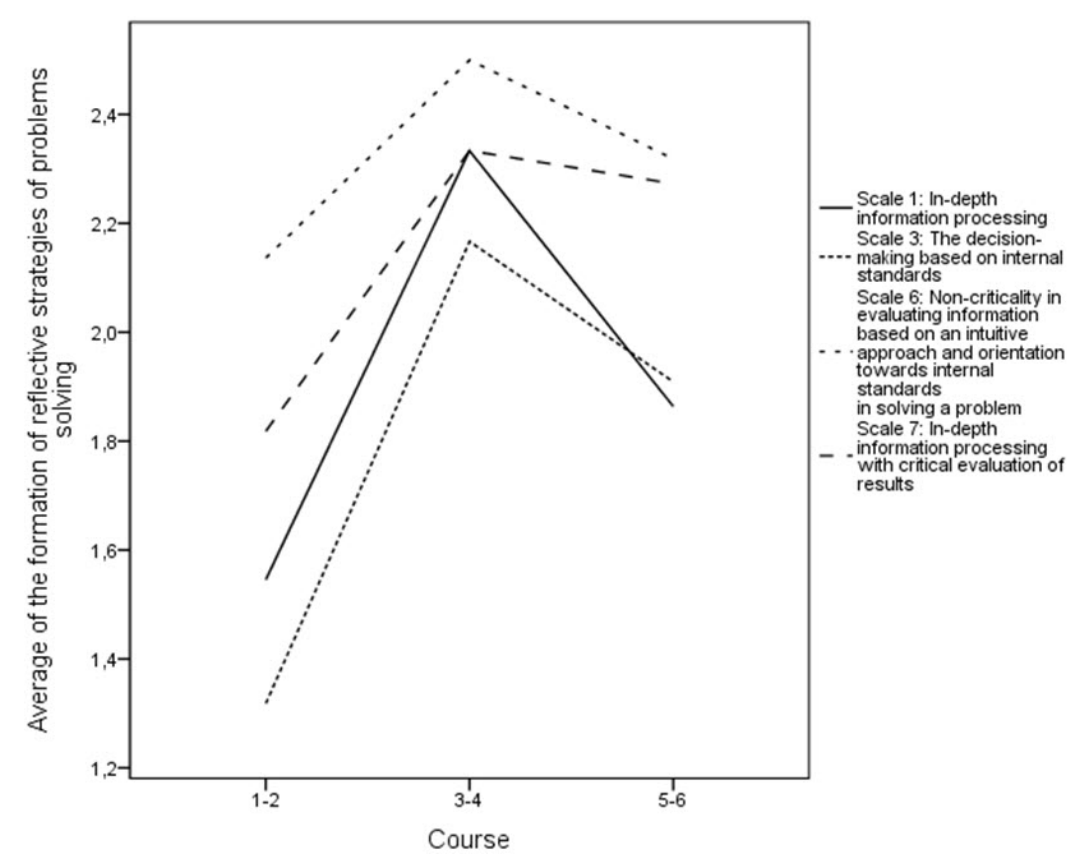

Figure 3. The results of the method "The reflexive strategies of problems solving" $(0$. Savchenko, M. Makiienko) in the development among students in accordance with the curriculum with the use of onefactor dispersion analysis of variance ANOVA

It is also worth noting that such a metacognitive characteristic as metacognitive knowledge correlates with the vast majority of reflexive strategies, in particular, a positive weak link with deep processing of information ( $r=0.286, p=0.024)$, criticality in the analysis and evaluation of information $(r=0.277, p=0.029)$, a rational approach to solving a problem with an orientation towards internal standards ( $r=0253, p=0.048)$, as well as a positive moderate link with decision-making with an orientation to internal standards $(r=0.373$, $p=0.003$ ), non-criticality in evaluating information based on an intuitive approach and focus on internal standards in solving the problem $(r=0.450, p=0.000)$ (See Table 3 ).

This means that the more involved, active, and knowledgeable a person is about their own metacognitive activity and their ability to consciously monitor and change his or her actions, the more reflexive problem-solving strategies he or she has. Considering the most informative results of correlation analysis, we can state that such a component of reflexive strategies as the orientation towards internal standards in problem-solving has a close connection with metacognitive knowledge and involvement. That is, a student who possesses these metacognitive characteristics is inclined to solve problems based on his or her thoughts and strengths, and not the requirements and assessments of others. 


\section{Table 3}

The results of the correlation analysis with the use of Spearmen's correlation coefficient on the connection between metacognitive characteristics and reflective strategies of problems solving

\begin{tabular}{|c|c|c|}
\hline \multirow{2}{*}{\multicolumn{3}{|c|}{ Metacognitive activity * }} \\
\hline & & \\
\hline $\begin{array}{l}\text { Non-criticality in evaluating information based on an intuitive approach and } \\
\text { orientation towards internal standards in solving a problem } \\
\text { Metacognitive activity * }\end{array}$ & 0,261 & 0,041 \\
\hline $\begin{array}{l}\text { Rational approach to solving a problem with an orientation towards internal } \\
\text { standards }\end{array}$ & 0,306 & 0,016 \\
\hline $\begin{array}{l}\text { Metacognitive knowledge * } \\
\text { In-depth information processing }\end{array}$ & 0,286 & 0,024 \\
\hline $\begin{array}{l}\text { Metacognitive knowledge * } \\
\text { Criticality in the analysis and evaluation of information }\end{array}$ & 0,277 & 0,029 \\
\hline $\begin{array}{l}\text { Metacognitive knowledge * } \\
\text { Decision-making based on internal standards } \\
\text { Metacognitive knowledge * }\end{array}$ & 0,373 & 0,003 \\
\hline $\begin{array}{l}\text { Non-criticality in evaluating information based on an intuitive approach and } \\
\text { orientation towards internal standards in solving a problem }\end{array}$ & 0,450 & 0,000 \\
\hline $\begin{array}{l}\text { Metacognitive knowledge * } \\
\text { Rational approach to solving a problem with a focus on internal standards }\end{array}$ & 0,253 & 0,048 \\
\hline $\begin{array}{l}\text { Metacognitive involvement * } \\
\text { Rational approach to finding a solution to a problem }\end{array}$ & 0,347 & 0,006 \\
\hline $\begin{array}{l}\text { Metacognitive involvement } \\
\text { Rational approach to solving a problem with a focus on internal standards }\end{array}$ & 0,722 & 0,000 \\
\hline
\end{tabular}

Students can evaluate and quickly correct their actions, anticipate possible failures, and change the way he or she accomplishes the task accordingly.

\section{Discussion}

In the light of the results of our theoretical analysis and empirical research, with the help of statistical analysis, we confirmed the hypothesis that there is a positive connection between the metacognitive characteristics of the subject's activity, namely metacognitive involvement, activity, and knowledge, and formed reflexive problem-solving strategies; that is, the more metacognitive characteristics the subject has developed, the more effective it is to use reflexive strategies to solve the problems. This result is consistent with some psychological studies about metacognitive involvement and monitoring (Avhustiuk, 2016; Balashov, 2019; Dotsevych, 2014; Flavell, 1979; Karpov, 2012; Nietfeld et al., 2005).

Reflexive competence is a mobilizing factor for triggering the operational and behavioral resources of the individual, through which the activity of the subject is ensured by the organization and regulation of intellectual activity. Enhanced operations and strategies reduce the ability to use poorly performing techniques to process information and to lose control over the course of one's thoughts and experiences. Reflexive competence at the metacognitive level is viewed as a system of formed reflexive abilities, which ensures high productivity of the intellectual activity of the subject by activating the metacognitive resources that are necessary and organizing reflexive actions aimed at eliminating the problem in the situation when it is necessary to solve a difficult task. The quality and content of a person's decision is largely mediated by the way, in which the subject evaluates his or her knowledge and intellectual skills in the process of completing a particular task. It is worth noting that most of the studies show that the actor is inclined to overestimate one's own competence. For this reason, student's overconfidence can cause mistakes in the evaluation of the results of the work on the task. Today, much of the research is focused on exploring the various factors that determine the quality of metacognitive monitoring and its potential for development. Thus, senior students have better indicators of reflexive skills at the metacognitive level, among which it is necessary to distinguish abilities: to organize the process of solving a problem, to direct efforts towards the goal, to predict possible mistakes and difficulties, to analyze one's own capabilities, 
and to plan, evaluate and check one's own actions. Our study has proved that reflexive competence of students at the metacognitive level has been confirmed to be closely interconnected with the components of metacognitive learning activities of students, supporting the studies of Schunk (1987), Dunlosky and Metcalfe (2009), Winne (2010), Savchenko (2016).

At the same time, the indicators of the level of development of the reflexive skills at the cognitive level are lower, namely the following abilities: to comprehend one's own emotional experiences, to control their course, to maintain a sense of confidence, to explain to themselves and others the course of their own reasoning and reasons for choosing a certain solution or strategy. Master's students also have more sophisticated reflexive problem-solving strategies, such as in-depth information processing, internal standards-based decision-making, deep processing of information with critical evaluation of results, and more. Such results support the previous studies of Valdez (2013), Ryan and Deci (2017), Kitsantas and Dabbagh (2010), Leontyev and Averyna (2011) who emphasized the importance of reflexivity and selfdetermination in success of learning process.

\section{Conclusions}

The results of the presented study indicate that senior students (master's program) have a higher level of reflexive skills at the metacognitive and cognitive levels and, accordingly, have a higher level of reflexive problem-solving strategies than the first- and second-year students have. At the same time, the results of the comparison of the general level of development of the reflexive skills at the cognitive level revealed that the senior students (master's program) have the lowest indicators. However, such a result may be due to sample characteristics (our study is not a longitudinal one), rather than age differences or the dynamics of learning activity.

Positive correlation between the metacognitive characteristics of the student learning activity, namely metacognitive involvement, activity, and knowledge, and the formed reflexive problem-solving strategies have been confirmed. The more metacognitive characteristics a student develops, the more effective it is to use reflexive strategies to solve the learning problems. We have found out that reflexive cognitive skills do not have a positive link at both levels (metacognitive and cognitive) or not correlate with metacognitive activity, while reflexive metacognitive skills do not correlate with metacognitive knowledge.

\section{Acknowledgments}

Authors would like to express sincere words of gratitude to all participants of the research (students of the National University of Ostroh Academy) and to the editorial team members for their patience, kindness and professional assistance.

\section{Conflict of interests}

The authors declare no conflict of interest.

\section{References}

Andrade, H. L., \& Heritage, M. (2017). Using formative assessment to enhance learning, achievement, and academic selfregulation. Routledge. https://doi.org/10.4324/9781315623856

Avhustiuk, M. (2016). Psychological Peculiarities of Objectivity of Metacognitive Monitoring. Actual Issues of Development of Education and Science under Conditions of Globalization. Materials of All-Ukrainian Scientific Conference. Dnipro: Royal Print, 35-37. Retrieved from http://www.dnu.dp.ua/docs/zbirniki/fsnm/program_5a1d359d68327.pdf

Babaian, Y. (2014). Structure of Reflexive Competence of Teacher of Higher School. Scientific Bulletin of O. Sukhomlynskyi Mykolaiv National University. Series "Psychological Sciences", 2(13), 22-26.

Balashov, E. (2019). Psychological characteristics of metacognitive monitoring in student learning activities. Scientific Bulletin of Kherson State University. Series "Psychological Sciences", 4, 64-71. https://doi.org/10.32999/ksu2312-3206/20194-8

Balashov, E., Pasichnyk, I., \& Kalamazh, R. (2018). Self-Monitoring and Self-Regulation of University Students in Text Comprehension. Psycholinguistics, 24(1), 47-62. https://doi.org/10.31470/2309-1797-2018-24-1-47-62

Bandura, A. (1997). Self-efficacy: The exercise of control. New York, NY: Freeman.

Bembenutty, H., Kitsantas, A., \& Cleary, T. J. (Eds.). (2013). Applications of selfregulated learning across diverse disciplines: A tribute to Barry J. Zimmerman. IAP.

Dabbagh, N., \& Kitsantas, A. (2013). The role of social media in self-regulated learning. International Journal of Web Based Communities, 9(2), 256-273. https://doi.org/10.1504/IJWBC.2013.053248

Dotsevych, T. I. (2014). Rozroblennia i aprobatsiia opytuvalnyka pedahohichnoi refleksyvnosti vykladacha vyshchoi shkoly 
Balashov et al. (2020). Reflexive competence in metacognitive monitoring of learning activity of HEl students, International Journal of Cognitive Research in Science, Engineering and Education (IJCRSEE), (8), Special issue of Current Research and Trends in Cognitive Sciences 2020, 17-28.

[Designing and approbation of questionnaire of reflexivity of a HEl teacher]. Psykholohichni perspektyvy-Psychological Perspectives, 23, 99-112.

Dovhaliuk, T. \& Voloshyna, V. (2015). Poniattia myslennia yak metakohnityvnoho protsesu u psykholohichnii nautsi [Concept of Thinking as Metacognitive Process in Psychological Science]. Molodyi vchenyi-Young Scientist, 10(25), 184-188. Retrieved from http://molodyvcheny.in.ua/files/journal/2015/10/84.pdf

Dunlosky, J., \& Metcalfe, J. (2009). Metacognition: A Textbook for Cognitive, Educational, Life Span and Applied Psychology. SAGE Publications

Flavell, J. H. (1979). Metacognition and cognitive monitoring: A new area of cognitive-developmental inquiry. American psychologist, 34(10), 906-911. https://doi.org/10.1037/0003-066X.34.10.906

Fomin, A. Y. (2012). Evrystika dostupnosti i metakohnitivnyi monitorynh resheniia uchebnykh zadach studentami [Heuristics of availability and metacognitive monitoring of solving learning tasks by students]. Psykhologiia: Vestnik Brianskogo hosuniveriteta, 1, 175-180. [in Russian]. Retrieved from http://vestnik-brgu.ru/wp-content/numbers/v2012_12.pdf

Hrynkiv, A. (2016). Metacognitive Researches in Context of Educational Innovations. Higher Education of Ukraine, 2, 37-43. Retrieved from http://enpuir.npu.edu.ua/bitstream/123456789/19188/1/Grinkiv.pdf

Karpov, A. (2012). Interconnection of Learning and Metacognitive Characteristics of Personality. Yaroslavl Pedagogical Bulletin, 2(3) (Psychological and Pedagogical Sciences), 228-235. Retrieved from http://vestnik.yspu.org/ releases/2012_3pp/51.pdf

Kholodnaya, M. (2002). Psychology of Intellect: Paradoxes of Research. Saint Petersburg: Piter.

Kitsantas, A., \& Dabbagh, N. (2013). Learning to Learn with Integrative Learning Technologies (ILT): A Practical Guide for Academic Success (Chinese Edition). IAP.

Kitsantas, A. \& Dabbagh, N. (2010). Learning to learn with Integrative Learning Technologies (ILT); A Practical Guide for Academic Success. Charlotte: NC: Information Age Publishing.

Koriat, A., \& Bjork, R. A. (2005). Illusions of competence in monitoring one's knowledge during study. Journal of Experimental Psychology: Learning, Memory, and Cognition, 31(2), 187-194. https://doi.org/10.1037/0278-7393.31.2.187

Leontyev, D., \& Averyna, Z. (2011). Phenomenon of Reflexivity in Context of Issue of Self-Regulation [E-Resourse]. Psychological Research: Electronic Scientific Journal, 2(16). Retrieved from http://psystudy.ru/index.php/num/2011n216/463-leontiev-averina16.html

Maksymenko, S. (2017). Genetic Psychology of Human Learning [E-Resource]. Kyiv: Slovo. Retrieved from http://lib.iitta.gov. ua/id/eprint/709727.

Nelson, T.O. \& Narens, L. (1990). Metamemory: A theoretical framework and some new findings. In G.H. Bower (Ed). The Psychology of Learning and Motivation, (Vol. 26, pp. 125-173). New York: Academic Press.

Nietfeld, J. L., Cao, L., \& Osborne, J. W. (2005). Metacognitive monitoring accuracy and student performance in the postsecondary classroom. The Journal of Experimental Educational, 74(1), 7-28. https://www.jstor.org/stable/20157410

Pasichnyk, I., Kalamazh, R., \& Avhustiuk, M. (2014). Metakohnityvnyi monitorynh yak rehuliatyvnyi aspect metapiznannia [Metacognitive experience as regulative aspect of metaknowledge]. Naukovi zapysky Natsionalnoho universytetu "Ostrozka akademiia»-Scientific Notes of the National University of Ostroh Academy. Series «Psychology and Pedagogy». Thematic Issue «Actual Problems of Cognitive Psychology, 28, 3-16. Retrieved from https://psj.oa.edu.ual articles/2014/n28-ua/Pasisnik.pdf

Pasichnyk, I. \& Dovhaliuk, T. (2016). Feedback as a Factor of Optimization of Metamemory under the Conditions of Proactive Interference. Scientific Notes of National University of Ostroh Academy. Series "Psychology", 4, 5-18. Retrieved from https://eprints.oa.edu.ua/7503/1/3.pdf

Ryan, R. M., \& Deci, E. L. (2017). Self-determination theory: Basic psychological needs in motivation, development, and wellness. Guilford Publications.

Savchenko, O. (2016). Reflexive Competence of Personality: monograph. Kherson: Helvetyka.

Savin, E. \& Fomin, A. (2011). Confidence in Knowledge as Aspect of Metacognitive Monitoring in Learning Activity. Scientific Works of K. Tsyolkovskiy Kaluga State University. Series "Psychological and Pedagogical Sciences", $244-248$. Retrieved from http://evgenysavin.ru/_Id/0/61___2011. .pdf

Schunk, D. (1987). Self-Efficacy and School Learning. Psychology in Schools, 22(2), 208-223. https://doi.org/10.1002/15206807(198504)22:2<208::AID-PITS2310220215>3.0.C0:2-7

Tytarenko, T. (2013). Individuality-Oriented Approach in Practical Psychology. Psychology and Personality, 1(3), 85-96. Access Mode: http://nbuv.gov.ua/UJRN/Psios 2013 19

Valdez, A. (2013). Student Metacognitive Monitoring: Predicting Test Achievement from Judgment Accuracy. International Journal of Higher Education, 2(2), 141-146. https://doi.org/10.5430/ijhe.v2n2p141

Winne, P. H. (2010). Bootstrapping learner's self-regulated learning. Psychological Test and Assessment Modeling, $52(4), 472$.

Zabrucky, K. M. (2010). Knowing what we know and do not know: Educational and real world implications. Procedia-Social and Behavioral Sciences, 2(2), 1266-1269. https://doi.org/10.1016/j.sbspro.2010.03.185

Zimmerman, B. J., \& Schunk, D. H. (2011). Handbook of self-regulation of learning and performance. Routledge/Taylor \& Francis Group. 